\title{
Atypical presentation of testicular torsion: a case series
}

\author{
Uzodimma Ejike Onwuasoanya*
}

\begin{abstract}
Background: Testicular torsion is a urological emergency and needs urgent intervention to prevent testicular loss and impaired future fertility. It is commonly seen in the neonatal and adolescent age groups. Testicular torsion can also present outside these common age groups with uncommon symptoms and signs. We report case series of patients managed at Lily Hospitals Limited, Warri, Delta State, Nigeria with atypical presentation of testicular torsion.

Case Presentation: The first patient was a 35-year-old male that presented with recurrent right testicular pain of 1 -year duration, described as dull aching with no constitutional symptoms, physical examination findings were not pathognomonic of testicular torsion, he had scrotal exploration with right orchidectomy and left orchidopexy. The second patient was a 39-year-old male who presented with recurrent right testicular pain of 4-days duration, described as dull aching with no constitutional symptoms. Physical examination findings were not classical for testicular torsion, he had scrotal exploration with bilateral orchidopexy.

Conclusion: Testicular torsion although common in neonatal and adolescent age groups can also present outside these age groups with uncommon symptoms and signs, a high index of suspicion is thus invaluable in any patient presenting with testicular pain despite the age and severity to avoid missing the diagnosis as this can lead to testicular loss.
\end{abstract}

Keywords: Atypical, Testicular, Torsion, Presentation

\section{Background}

Testicular torsion is the most common cause of rapid onset testicular pain and swelling in people under 18 years old [1]. It was first described by Louis Delasiauve in 1840 [2]. It occurs in about 1 in 4,000 to 1 in 25,000 males under 25 years of age $[3,4]$. Testicular torsion occurs when the spermatic cord twists, cutting off blood supply to the testicle [4]. Urgent treatment is thus needed to salvage the testis and avert the need for orchidectomy.

The diagnosis of testicular torsion can be difficult because some diseases have similar presentation such as acute epididymo-orchitis and torsion of testicular appendages, even the most prudent clinician cannot make the distinction between these conditions with absolute certainty. Currently, there is no precise template to be followed for management of suspected testicular torsion. Sequel to this, there is no investigation with $100 \%$ specificity and sensitivity in the diagnosis of testicular torsion.

The conventional management has been clinical review followed by surgical exploration but this has led to several unnecessary surgeries with increased morbidity and cost for the patients concerned.

Testicular torsion can be present in an atypical form and outside the common age of occurrence, thus a high index of suspicion is invaluable in patients with complaint of scrotal pain despite the age with thorough evaluation to avoid missing the diagnosis of testicular torsion as such can lead to testicular loss.

\footnotetext{
*Correspondence: ejike31@gmail.com

Department of Urology, Lily Hospitals Limited, Warri, Delta State, Nigeria
} original author(s) and the source, provide a link to the Creative Commons licence, and indicate if changes were made. The images or other third party material in this article are included in the article's Creative Commons licence, unless indicated otherwise in a credit line to the material. If material is not included in the article's Creative Commons licence and your intended use is not permitted by statutory regulation or exceeds the permitted use, you will need to obtain permission directly from the copyright holder. To view a copy of this licence, visit http://creativecommons.org/licenses/by/4.0/. 


\section{Case presentation}

\subsection{Case 1}

A 35-year-old male who presented with recurrent right testicular pain of 1-year duration, the pain was dull aching, does not radiate to any part of the body, not worse at any time of the day, relieved by analgesics, not associated with lower urinary tract symptoms, urethral discharge, nausea, vomiting, fever or abdominal pain. There was no history of scrotal trauma or multiple sexual partners, and there was no history of drug allergy, past surgeries nor family history of testicular torsion.

Physical examination revealed enlarged right testis that was not tender, normal lie, preserved cremasteric reflex with indeterminate Prehn sign. Doppler ultrasound scan of the scrotum revealed right epididymo-orchitis with decreased blood flow in the right testis.

A diagnosis of recurrent right testicular torsion was made, and he had emergency scrotal exploration with findings of non-viable right testis (Fig. 1) at 90 degrees torsion, inflamed right testis and epididymis. He subsequently had right orchidectomy and left orchidopexy with uneventful post-operative recovery, he was discharged 2 days after surgery and is currently on followup visits with complete resolution of the scrotal pains. Histopathology of the right testis revealed ischaemic necrosis.

\subsection{Case 2}

A 39-year-old male who presented with recurrent right testicular pain of 4-days duration, it was dull aching, does not radiate to any part of the body, not worse at any time

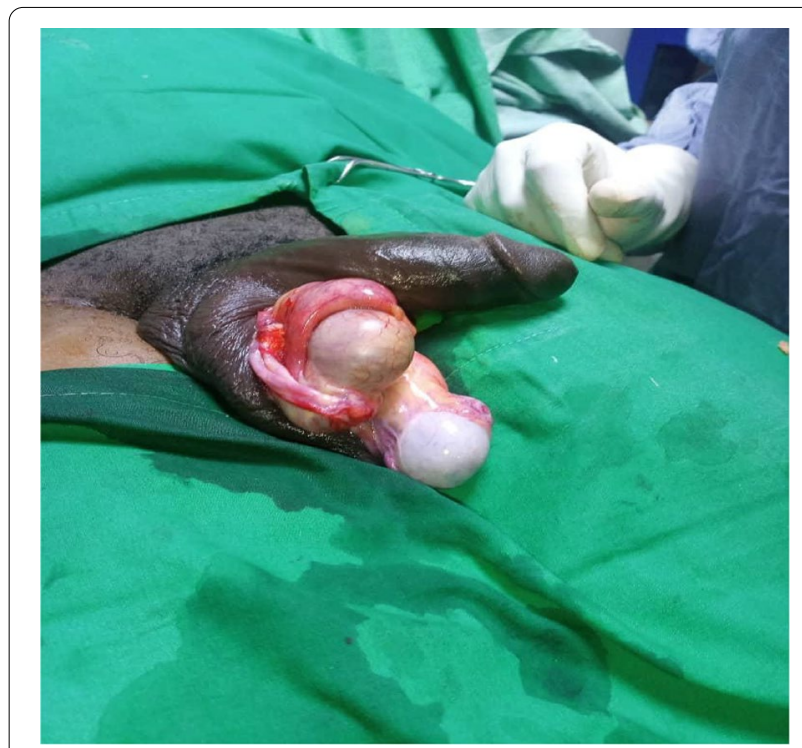

Fig. 1 Scrotal exploration revealing non-viable and inflamed right testis of the day, relieved by analgesics, not associated with lower urinary tract symptoms, urethral discharge, nausea, vomiting, fever or abdominal pain. There was no history of perineal trauma or multiple sexual partners, and no history of drug allergies, past surgeries or family history of testicular torsion.

Physical examination revealed non-tender right testis with normal lie and testicular volume. Cremasteric reflex was preserved with indeterminate Prehn sign. Doppler ultrasound scan of the scrotum revealed decreased blood flow in the right testis.

A diagnosis of recurrent right testicular torsion was made, and he had emergency scrotal exploration with findings of partially viable right testis (Fig. 2) at 180 degrees torsion, he had de-torsion of the right testis with bilateral orchidopexy. Post-operative recovery was uneventful, and he was discharged 2 days after surgery. He is currently on follow-up visits with complete resolution of the scrotal pains.

\section{Discussion}

Testicular torsion in its intravaginal form usually presents itself in ages between 3 and 20 years but is more common in post-pubescent period with a $65 \%$ incidence rate occurring between the ages of 12-18 [5]. Both patients managed at our facility presented outside the common age of occurrence of testicular torsion, this made initial suspicion of this disease difficult and buttressed the fact that any testicular pain at any age should be thoroughly evaluated to rule out testicular torsion as it can occur at any age.

The predisposing factor to testicular torsion in our patients could only be attributed to physical activity after thorough evaluation of the patients. Previous studies done revealed that physical activity, testicular

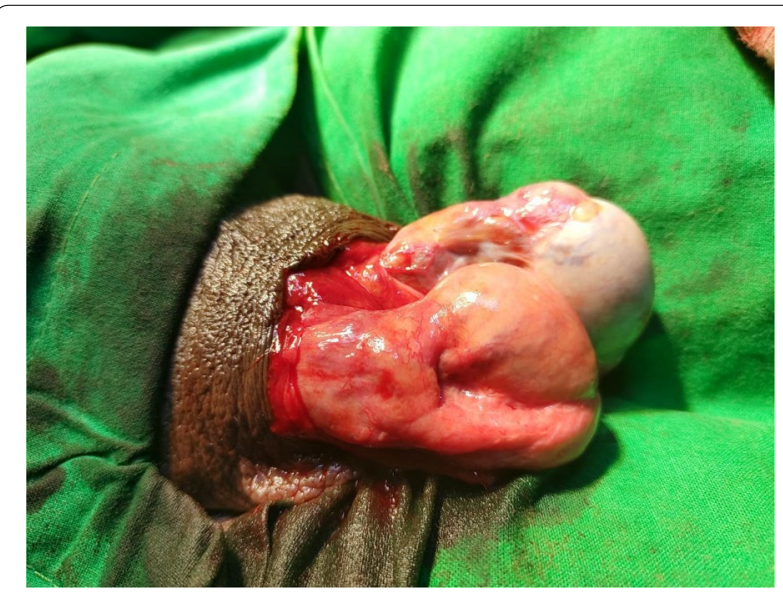

Fig. 2 Scrotal exploration revealing partially viable right testis 
volume growth, cold climate, trauma and hyperactivity of the cremasteric reflex compose some of the known predisposing factors to testicular torsion [5-7]. Jesus LE noted that sudden local intense pain, oedema, progressive hyperaemia in the scrotum, hardening and volume growth, with elevated and horizontalized position of the testis with torsion were common presentation of testicular torsion [6]. Both patients in this study presented with dull aching testicular pain that was intermittent and not commonly attributed to testicular torsion pain. The first patient also presented with oedema, hardening and volume growth of the affected testis, but these were not seen in the second patient managed. The affected testis was not tender on physical examination for both patients managed, this finding also is unusual for testicular torsion examination. Elevation and horizontal position of the affected testis were not seen in both patients managed.

Doppler ultrasound scan has been noted to have good sensitivity and specificity for the diagnosis of testicular torsion and is the main preliminary examination to detect and confirm this disease [8]. Doppler ultrasound scan revealed decreased blood flow in the affected testis for both patients managed, it also revealed features of local inflammation in the affected testis of the first patient managed which is in keeping with the sequelae of testicular torsion. Common Doppler ultrasound finding in testicular torsion is absent blood flow in the affected testis, the Doppler ultrasound scan finding in both patients managed was not also in keeping with the usual finding in testicular torsion.

Bolin and colleagues in their study noted that contralateral orchidopexy can be performed regardless of the viability of the affected testicle [9]. The patients managed had contralateral orchidopexy despite the outcome of scrotal exploration for the affected testis. The reason for contralateral orchidopexy is due to the main predisposing factor for intravaginal testicular torsion which is bell-clapper deformity. This deformity increases testicular mobility and therefore the risk of torsion is bilateral in up to $80 \%$ of patients [10]. The first patient unfortunately had orchidectomy for the affected testis as the incomplete torsion has been persistent for long with associated local inflammatory changes unlike the second patient managed. Apart from thorough evaluation of patients presenting with testicular pain, there is also a need for public enlightenment to visit urology clinic for any testicular pain no matter the severity. The first patient managed never presented to the urology clinic till after a year and as such the testis could not be salvaged.

\section{Conclusion}

Testicular torsion although common in the neonatal and adolescent age groups can also occur outside these age groups.

The classical sudden intense pain of testicular torsion is often absent in incomplete testicular torsion, as well as the classical physical examination findings.

High index of suspicion is thus invaluable in any patient presenting with testicular pain despite the age or severity of the pain to avoid missing the diagnosis of testicular torsion as this can lead to testicular loss.

\section{Acknowledgements \\ Not applicable.}

\section{Authors' contributions}

The single author is solely responsible for the design and implementation of the research, the collation of materials needed to write the manuscript and the writing of the manuscript.

Funding

None.

Availability of data and materials

Not applicable.

\section{Declarations}

Ethics approval and consent to participate Not applicable.

Consent for publication

A written consent was obtained from the patient.

Competing interests

The author has no competing interest.

Received: 12 March 2021 Accepted: 11 July 2021

Published online: 21 July 2021

\section{References}

1. Edelsberg JS, Surh YS (1998) The acute scrotum. Emerg Med Clin North Am 6:521-546

2. Heyns CF, Visser AJ. Testicular Torsion. In: Schill WB, Comhaire FH, Hargreave TB (eds) (2006) Andrology for the clinician, 1st edn. Springer Science and Business Media

3. Sharp VJ, Kieran K, Arlen AM (2013) Testicular torsion: diagnosis, evaluation and management. Am Fam Phys 88:835-840

4. Wampler SM, Lianes M (2010) Common scrotal and testicular problems. Prim Care 37:613-626

5. Arce JD, Cortes M, Vargas JC (2002) Sonographis diagnosis of acute spermatic cord torsion. Ped Radiol 32:485-491

6. Jesus LE (2000) Acute Scrotum. Revista do Colegio Brasileiro de Cirurgioes 27:271-278

7. Korkes F, Cabral PR, Alves CD, Savioli ML, Pompeo AC (2012) Testicular torsion and weather conditions: analysis of 21,289 cases in Brazil. Int Braz J Urol 38:222-229

8. Mosconi A, Claro JFdeA, Andrade E, Vicentini F, Paranhos MLdaS (2008) Acute scrotum. Rev Med 87:178-183

9. Bolin C, Driver CP, Youngson GG (2006) Operative management of testicular torsion: current practice within the UK and Ireland. J Pediatr Urol 2:190-193 
10. Favorito LA, Cavalcante AG, Costa WS (2004) Anatomic aspects of epididymis and tunica vaginalis in patients with testicular torsion. Int Braz J Urol 30:420-424

\section{Publisher's Note}

Springer Nature remains neutral with regard to jurisdictional claims in published maps and institutional affiliations.

\section{Submit your manuscript to a SpringerOpen ${ }^{\circ}$} journal and benefit from:

- Convenient online submission

- Rigorous peer review

- Open access: articles freely available online

- High visibility within the field

- Retaining the copyright to your article

Submit your next manuscript at $\boldsymbol{\nabla}$ springeropen.com 